\title{
LA ESTRUCTURA DEL PRIMER BANCO PÚBLICO de Europa: la Taula de Canvi de Barcelona $($ SIGLO XV)
}

\author{
Laura Miquel Milian² \\ Institució Milà i Fontanals - CSIC
}

Recibido: 22 de mayo de 2019

Aceptado: 7 de septiembre de 2019

\section{Resumen}

El objetivo principal de este estudio es reconstruir el organigrama de la Taula de Canvi de Barcelona desde su nacimiento en 1401 hasta el final del siglo XV. Concretamente, se pasa revista a los oficiales que trabajaron en el banco durante este periodo, intentando establecer claramente cuáles eran sus funciones y cómo evolucionaron a lo largo del Cuatrocientos. Asimismo, se analizan los cambios documentados en su número y en su salario, estrechamente relacionados con las reivindicaciones de tipo laboral que hicieron al municipio. Por último, también se muestran algunos de los principales problemas que afectaron el buen funcionamiento de la Taula durante dicho siglo.

\section{Palabras clave}

Barcelona, Taula de Canvi, Consell de Cent, baja edad media, historia institucional.

\begin{abstract}
The aim of this paper is to reconstruct the organisation chart of the Taula de Canvi of Barcelona, from its inception in 1401 until the end of the $15^{\text {th }}$ century. More specifically, it takes a look at the officers who worked in the bank during that period of time, in order to establish what their roles were and how that roles evolved over the 1400s. Likewise, the changes documented in their number and salaries are analysed, both aspects closely connected to their labor-related claims to the municipality. Al last, some of the main problems that affected the correct functioning of the Taula during that century are also shown.
\end{abstract}

\section{Keywords}

Barcelona, Taula de Canvi, Consell de Cent, Late Middle Ages, Institutional History.

\footnotetext{
1 Trabajo ganador del XIX premio Medievalismo concedido por la Sociedad Española de Estudios Medievales. Este artículo se inscribe en el proyecto de investigación «La desigualdad económica en las ciudades catalanas y mallorquinas durante la Baja Edad Media» (ref. PGC2018-100979-B-C22), y se ha realizado en el marco del Grup de Recerca Consolidat «Renda feudal i fiscalitat a la Catalunya baixmedieval» (2017SGR1068). Abreviaturas utilitzadas: AHCB=Arxiu Històric de la Ciutat de Barcelona; f.= folio $(\mathrm{r} .=$ recto, $\mathrm{v} .=$ verso); 11., s., d.b. $=$ libras, sueldos, dineros barceloneses.

2 Institució Milà i Fontanals-CSIC, Barcelona. Correo electrónico: laura.miquel@imf.csic.es. Orcid: https://orcid.org/0000-0001-5530-8123.
} 


\begin{abstract}
Resum
L'objectiu principal d'aquest estudi és reconstruir l'organigrama de la Taula de Canvi de Barcelona des del seu naixement l'any 1401 fins al final del segle XV. Concretament, es passa revista als oficials que van treballar al banc durant aquest període, intentant establir clarament quines eren les seves funcions i com van evolucionar al llarg del Quatre-cents. Així mateix, s'analitzen els canvis documentats en el seu nombre $i$ en el seu salari, estretament relacionats amb les reivindicacions de caire laboral que van fer al municipi. Per últim, també es mostren alguns dels principals problemes que van afectar el bon funcionament de la Taula durant el dit segle.
\end{abstract}

\title{
Paraules clau
}

Barcelona, Taula de Canvi, Consell de Cent, baixa edat mitjana, història institucional

\section{Introducción}

Como es sabido, la Taula de Canvi de Barcelona, nacida en 1401 y situada en la Llotja de Mar, es considerada por muchos estudiosos el primer banco público de Europa, idea que en los últimos años ha sido cada vez más defendida. Gaspar Feliu, por ejemplo, lo afirma de forma contundente, oponiéndose a los historiadores que otorgan esta primacía al Banco di San Giorgio de Génova; aunque también Giuseppe Felloni, uno de los principales estudiosos del banco genovés, comenta que "Come banco pubblico medievale, [San Giorgio] fu il primo in Italia ed il secondo in Europa dopo la Taula de cambi di Barcellona" ${ }^{3}$. Por lo que respecta al carácter público de la Taula, este venía dado por el hecho de que la garante de los depósitos era la riqueza del conjunto de habitantes de la ciudad 4 .

Sea como sea, la originalidad y relevancia de esta institución, cuyo nombre oficial era "Taula de Canvi assegurada de la Ciutat de Barcelona" o bien "Taula de Canvi i de comuns dipòsits", ha provocado que haya sido vista por diversos historiadores como un interesante objeto de estudios. Ya en la década de 1940 Abbot Payson Usher le dedicó una importante parte de su obra The early history of deposit banking in Mediterranean Europe, ocupándose de la creación de la Taula y de su relación con las finanzas municipales, entre otros temas ${ }^{6}$. Más recientemente, destacan las contribuciones realizadas por Gaspar Feliu y Pere Orti, que se han centrado de modo particular en el funcionamiento

\footnotetext{
Feliu i Montfort, Els primers llibres de la Taula de Canvi, pp. 9-10, 37-38; Felloni, "L'archivio della Casa di San Giorgio", p. 356. Todavía en otro artículo Felloni comenta que "Nel 1408, intanto, ad imitazione di quanto s'era fatto nel 1401 a Barcellona, l’Ufficio di San Giorgio aveva creato un banco pubblico, ossia un'azienda sottoposta al controllo pubblico e specializzata nell'attività bancaria, che nel suo genere fu la seconda in Europa (dopo quella di Barcellona) e la prima in Italia" (Felloni, "Il Banco di San Giorgio ed il suo archivio", pp. 461-462).

4 ORTi Gost, "Les finances municipals de la Barcelona dels segles XIV i XV”, pp. 272-273

5 Feliu i Montfort, Els primers llibres de la Taula de Canvi, p. 38

6 UsHeR, The early history of deposit banking, pp. 237-504.
} 
de la Taula de Canvi durante sus primeros años de vida y en la estrecha vinculación entre esta y la tesorería del municipio, respectivamente?

Sin embargo, a día de hoy todavía no se ha llevado a cabo ninguna investigación dedicada a la organización y estructura de la Taula de Canvi que permita explicar quién trabajaba realmente en ella en cada momento de su dilatada historia. Es cierto que el cronista Esteve Gilabert Bruniquer, que vivió a caballo de los siglos XVI y XVII, ya menciona en sus Rúbriques la existencia de dos regidores, máximos responsables de la institución, y un escribano ${ }^{8}$. Por su parte, Gaspar Feliu, basándose en unas ordenanzas que sitúa en 1405, identifica los dichos regidores, dos o tres escribanos, que se encargarían de los libros de la Taula, y un pesador de florines ${ }^{9}$. Ahora bien, este listado de personal, más bien reducido, no deja de ser teórico, y en cualquier caso válido únicamente para un periodo de tiempo limitado. Resulta evidente que, por sencilla que fuera la composición inicial de la Taula, las autoridades de Barcelona rápidamente debieron darse cuenta que para gestionar el volumen de trabajo derivado de una institución como la que aquí nos ocupa hacía falta que los regidores contaran con la ayuda de múltiples oficiales auxiliares, de importancia capital. El principal objetivo de este trabajo es establecer exactamente qué cargos dependían de la Taula de Canvi durante su primer siglo de historia, es decir, cuáles eran los componentes de dicha institución. De este modo, podrá entenderse de forma más precisa su modus operandi cotidiano, tanto por lo que refiere al funcionamiento habitual como a las disfunciones que de vez en cuando afectaban el banco: desde los problemas por falta de personal o quejas por los reducidos salarios hasta los fraudes.

Si bien es cierto que la pérdida de cierta documentación, como las primeras ordenanzas del banco, dificulta esta tarea notablemente, existen otras fuentes que nos proporcionan noticias directas o indirectas sobre el personal de la Taula de Canvi en su primer siglo de vida. Concretamente, para poder llevar a cabo esta investigación ha sido necesario consultar distintas series custodiadas en el Arxiu Històric de la Ciutat de Barcelona, entre las cuales destacan Deliberacions y Clavaria. En la primera se recogen las actas de las reuniones del gobierno de la ciudad, que incluyen los nombramientos de cargos, mientras que en la segunda, dentro de la sección de gastos ordinarios satisfechos por el tesorero municipal, se encuentran los pagos de salarios. De esta forma, partiendo de los datos incluidos en dichos documentos así como en los pocos libros conservados de la propia Taula, y con la ayuda de la bibliografía existente, se intenta reconstruir el organigrama de la Taula de Canvi durante el siglo XV.

Feliu i Montfort, Els primers llibres de la Taula de Canvi; Orti Gost, "Les finances municipals de la Barcelona dels segles XIV i XV". Más allá de la Taula de Canvi, para una reciente relación de los primeros bancos públicos europeos véase Roberds, Velde, "Early Public Banks I".

8 Bruniquer i Sala, Rúbriques de Bruniquer, vol. 5, p. 75. Esta información ya fue recogida por Usher, The early history of deposit banking, p. 70.

9 Feliu i Montfort, Els primers llibres de la Taula de Canvi, p. 44. 


\section{Los administradores}

Los administradores de la Taula de Canvi, también llamados regidores o taulers, eran siempre dos, un miembro del estamento de los ciudadanos y uno del de los mercaderes ${ }^{10}$. $\mathrm{Su}$ presencia como responsables del banco está documentada desde el inicio de la institución, tal como muestra la entrada del 20 de enero de 1401 del Manual de novells ardits, el dietario del Consell: "Aquest dia fo posada e assegurada per la ciutat de Barchinona taula de cambi en la lotge nova per descarregar la dita ciutat de la qual taula foren regidors los honrats en Miquel Roure et en Guillem Colom" ${ }^{11}$. Según las citadas ordenanzas de 1405, el cargo de los administradores tenía que ser bienal, por lo que su regimiento empezaría el 20 de enero de cada año impar ${ }^{12}$. Vemos que esto se cumplió, por lo menos, los primeros años de existencia de la Taula, ya que el 20 de enero de 1403 "comensaren de usar per administradors" de la Taula los sucesores de Roure y Colom, que fueron Guillem Oliver y Pere de Casasaja ${ }^{13}$. Ahora bien, parece que al cabo de un tiempo esta tradición desapareció. A pesar de que en 1445 los administradores de la Taula sí que se designaron el 20 de enero, dos años después lo fueron el día 11, y en 1449 el 13. De modo similar, si nos fijamos en lo ocurrido durante la guerra civil catalana, por ejemplo, el Trentenari los nombró en un día no fijado de la segunda mitad de enero: en 1463 el día 24, en 1465 el 18, en 1467 el 26, y en 1469 y 1471 el $30^{14}$.

¿Cómo se llevaba a cabo esta elección? Según quedó anotado en el registro de Deliberacions del 24 de enero de 1463, en primer lugar los consellers se encargaban de confeccionar un memorial "de persones notables e suficients per al dit offici", que era leído a los jurados del Consell de Trenta ${ }^{15}$. Estos, si querían, podían modificar la lista añadiendo o eliminando algún nombre. Una vez esta había sido aprobada, tanto

\footnotetext{
10 Feliu i Montfort, Els primers llibres de la Taula de Canvi, p. 43. Durante los últimos siglos de la Edad Media la comunidad cívica barcelonesa se dividía en cuatro estamentos: ciudadanos, mercaderes, artistas y menestrales.

11 Manual de novells ardits, p. 87. Feliu señaló que Miquel Roure compartía nombre y apellido con uno de los consellers de Barcelona de ese año, atribuyéndolo a que probablemente eran parientes (FELIU I Montfort, Els primers llibres de la Taula de Canvi, p. 35, n. 1). Sin embargo, en el segundo libro de clavaria de ese año se dice claramente que Miquel Roure, regidor de la Taula, era también conseller (AHCB, 1B.XI, Clavaria, 26, f. 185v, 1-IX-1401).

12 Feliu i Montfort, Els primers llibres de la Taula de Canvi, p. 43.

13 Manual de novells ardits, vol. 1, p. 124.

$14 A H C B$, 1B.II, Deliberacions, 3, ff. 115r-115v, 20-I-1445; $A H C B$, 1B.II, Deliberacions, 4, ff. 85v-86r, 11-I-1447; $A H C B$, 1B.II, Deliberacions, 5, ff. 83v-84v, 13-I-1449; $A H C B$, 1B.II, Deliberacions, 15, ff. 106r, 24-I-1463; $A H C B$, 1B.II, Deliberacions, 16, f. 185r, 18-I-1465; $A H C B$, 1B.II, Deliberacions, 17, ff. 177v178r, 26-I-1467; $A H C B$, 1B.II, Deliberacions, 18, f. 141r, 30-I-1469; $A H C B$, 1B.II, Deliberacions, 20 , ff. $47 \mathrm{v}-48 \mathrm{r}, 30-\mathrm{I}-1471$.

15 Durante el siglo XV el gobierno de Barcelona estaba estructurado alrededor de tres instituciones básicas. En primer lugar se situaban los consellers, el gobierno ejecutivo, que ejercían el cargo durante un año. Estos magistrados podían ser asesorados por dos asambleas integradas por un número variable de jurados: la general, llamada normalmente Consell de Cent, y la reducida, el Consell de Trenta o Trentenari.
} 
los consellers como los miembros del Trentenari tenían que escribir el nombre de un ciudadano y el de un mercader en dos pequeñas cédulas de papel, que después eran introducidas en cajas. Terminado este proceso, solo quedaba hacer el escrutinio correspondiente para ver qué candidatos habían obtenido más votos ${ }^{16}$. Pocos días después, el 1 de febrero, los administradores prestaban juramento ante los consellers junto al resto de oficiales que trabajaban en la Taula ${ }^{17}$. Este sistema, más o menos alterado, debió ser el que imperó durante todo el siglo XV hasta la instauración de la insaculación. A partir de entonces, según quedó recogido en el privilegio otorgado por Fernando II a la ciudad de Barcelona el 13 de diciembre de 1498, el día de San Antonio -17 de enerolos taulers serían extraídos de dos bolsas, una de las cuales contendría únicamente el nombre de los candidatos ciudadanos y la otra de los mercaderes ${ }^{18}$.

Quizás sea en el mencionado acto de juramento donde se ve más claramente cuáles eran las funciones de los administradores de la Taula. Según el texto contenido en el manuscrito conocido como Rubrica de juraments antics, escrito seguramente a finales del siglo XV o principios del XVI, lo primero que juraban los regidores era que "be, feelment e leyals hauran en lo regiment, procuracio e administracio de la dita taula, cerqants per llur poder tota utilitat, squivant tot dan de la dita Ciutat sots obligacio de persona e bens hauts e havedors" ${ }^{19}$. No cabe duda de cuál era su cometido principal respecto a la Taula: dirigirla. Para hacerlo adecuadamente tenían que cumplir ciertas condiciones, que eran igualmente especificadas en el citado juramento. En primer lugar, no prestar ni librar más dinero a nadie del que tuviera depositado en la Taula, a no ser que los consellers o el Consell de Cent lo autorizaran. Seguidamente, tenían que encargarse de cobrar todo lo que se debiera al municipio, no pudiendo aceptar ningún tipo de favor o presente, aunque fuera en forma de comida o bebida, de ningún deudor. También tenían que comprometerse a no hacer pagos en nombre del clavario de la ciudad sin haber recibido previamente la orden correspondiente de los consellers $^{20}$, ni a participar de ningún modo en el arriendo de impuestos. Se les obligaba a mantenerse en el cargo hasta que sus sucesores hubieran prestado juramento, así como a dar una garantía de 6.000 florines en la corte del veguer, tal como

\footnotetext{
$16 A H C B, 1 B . I I$, Deliberacions, 15, f. 106r, 24-I-1463.

17 AHCB, 1B.II, Deliberacions, 15, ff. 111v-112r, 1-II-1463.

18 Vicens Vives, Ferran II i la ciutat de Barcelona, p. 294.

$19 A H C B$, manuscrito L-47, transcrito en BAJET Royo, El jurament i el seu significat juridic al Principat, pp. 146-48. La autora sitúa la confección del manuscrito a partir de 1483, ya que aparece mencionada una ordenanza municipal de ese año (BAJet Royo, El jurament i el seu significat jurídic al Principat, p. 17). Sin embargo, el hecho que al detallar el proceso de elección de los administradores de la Taula de Canvi mediante el sistema de la insaculación se mencione un privilegio otorgado por el rey Fernando II, que forzosamente tiene que ser el de 1498, situaría el texto después de dicho año (BAJET Royo, El jurament $i$ el seu significat jurídic al Principat, pp. 173-74).

20 En este albarà u orden de pago tenían que constar el nombre del receptor, la cantidad y el motivo de pago. Tras recibirlas, los regidores de la Taula tenían que enfilar los albarans para poder mostrarlos cuando se examinaran sus cuentas.
} 
hacían los cambistas al asegurar sus tablas ${ }^{21}$. Finalmente, debían jurar que cumplirían las ordenanzas promulgadas el 22 de agosto de $1476^{22}$.

Cabe recordar también que hasta el año 1588, cuando se inauguró la nueva sede de la Taula en un edificio situado frente a la Casa de la Ciutat, los libros y depósitos de la Taula de Canvi se custodiaban en casa de uno de los dos administradores ${ }^{23}$. Evidentemente, esta obligación de los taulers era de gran importancia, hecho que queda perfectamente ilustrado por un suceso que tuvo lugar en 1450, estando al frente del banco Joan Llull y Antoni Pujada. El año anterior la reina María había convocado Cortes en Perpiñán y Llull fue uno de los síndicos escogidos por Barcelona para asistir a la asamblea, de modo que en abril de 1450 dejó la ciudad para no volver hasta el diciembre siguiente ${ }^{24}$. Esto supuso un problema para la Taula, ya que era en casa de Llull donde se guardaban los libros y depósitos, ante lo cual el Consell se vio forzado a encontrar una rápida solución. Finalmente, a pesar de las reticencias iniciales de Pujada, se acordó que se le pediría a este último que se mudara a casa de Llull, si no "ab tota sa companya", por lo menos con un escudero para que -y esto era lo más relevante- estuviera, comiera, bebiera y durmiera allíí ${ }^{25}$.

Evidentemente, todas estas tareas tenían que ser debidamente recompensadas. Bruniquer ya comenta que cuando se inauguró la Taula de Canvi se estableció que los administradores recibirían un salario de 3.000 s.b., cantidad que también aparece en las ordenanzas de $1405^{26}$. Como puede observarse en los libros del clavario municipal, este sueldo fue válido ya desde 1401, y no se modificó hasta el año 1454, en el marco de la reforma administrativa impulsada por la Busca, cuando pasó a ser de 2.000 s.b. ${ }^{27}$.

\footnotetext{
21 Bajet indica que daban una garantía de 12 florines, aunque probablemente se trata de un error de transcripción. Es sabido que desde 1405 los administradores estaban obligados a dar una garantía de 6.000 florines cada uno (BRUniQuer i Riera, Rúbriques de Bruniquer, p. 76; Feliu i MontFort, Els primers llibres de la Taula de Canvi, pp. 42-43). Véanse, por ejemplo, las garantías de los 6.000 florines dados en 1435 por Bernat Fiveller y Berenguer Gibert en $A H C B$, 1B.II, Deliberacions, 1, f. 83v, 24-I-1435.

22 El objetivo de estas ordenanzas era establecer un control más estricto sobre la Taula por parte del municipio ( $A H C B$, 1B.IV, Ordinacions, 10, ff. 109v-111r, 22-VIII-1476).

23 Feliu i Montfort, Els primers llibres de la Taula de Canvi, pp. 48-49. La instalación de la Taula en casa de uno de los administradores a menudo provocaba que se tuvieran que hacer pequeñas obras. Así, en enero de 1477 -convenientemente poco antes de la elección de los nuevos taulers- Genís Caro, carpintero de la ciudad, pidió a los consellers que se estableciera que estas obras fueran adjudicadas a él, ya que, según decía, "los taulers los fan fer a altres fusters, a gran dan del dit seu offici". El Trentenari, considerando que era indigno que Caro tuviera "lo nom de l'offici [de carpintero de la ciudad] sens la comoditat", accedió ( $A H C B$, 1B.II, Deliberacions, 23, ff. 104r-105v, 10-I-1477).

24 Manual de novells ardits, vol. 2, pp. 59, 98.

25 AHCB, 1B.II, Deliberacions, 6, ff. 97r-97v, 16-IV-1450.

26 Bruniquer i Riera, Rúbriques de Bruniquer, p. 75; Feliu i Montfort, Els primers llibres de la Taula de Canvi, p. 43. Para Feliu, este salario sería demasiado bajo si se toma en consideración el estatus social de los administradores, las elevadas garantías de 6.000 florines que estaban obligados a dar y las responsabilidades que comportaban su cargo. Por este motivo, deduce que el cargo de administrador debía ejercerse a tiempo parcial.
}

27 Batlle i Gallart, La crisis social y económica de Barcelona, p. 274. 
No fue hasta el siguiente gran redreç municipal de Barcelona, el de 1489, que el salario de los taulers se rebajó de nuevo, esta vez a 1.000 s.b. anuales ${ }^{28}$.

\section{Los cargos técnicos}

Visto el papel jugado por los dirigentes del banco barcelonés, pasemos ahora a detallar cuáles eran los cargos técnicos necesarios para su funcionamiento. Como se verá seguidamente, estos pueden dividirse básicamente en tres grupos: el conformado por los escribanos, el de los pesadores y reconocedores de moneda, y, por último, el de los servidores y el bastaix.

\subsection{Los escribanos}

Los escribanos de la Taula de Canvi reciben en la documentación conservada y en la bibliografía existente varios apelativos. Gaspar Feliu a menudo los llama taulers adjuntos ${ }^{29}$, mientras que en las fuentes aparecen también como ayudantes de la Taula, regidores o continuadores de cuentas, o como encargados de alguno de los tres libros de la institución: el libro corriente, corrible o mayor corriente; el manual o diario, y el de depósitos.

Como se ha apuntado, los notarios que trabajaban de escribanos en la Taula se documentan como parte del personal fijo de la institución desde su nacimiento. Feliu indica los nombres de los dos adjuntos que documenta en la Taula desde 1401-1402 $2^{30}$, y bastante pronto, por lo menos desde 1414, parece que se añadió un tercer escribano como asistente del que ejercía de regidor de cuentas ${ }^{31}$. No fue hasta algún momento entre 1442 y 1446 que los tres escribanos de la Taula pasaron a designarse sistemáticamente en función del libro a su cargo (corriente, diario o depósitos), tradición que se mantuvo durante el resto del siglo $\mathrm{XV}^{32}$.

Los escribanos eran cargos vitalicios, hecho que ocasionalmente se constata en algún libro de clavaria: "és stat deputat (...) a regir e continuar los comptes de la dita Taula del Cambi de la dita ciutat a vida sua, tant com la Taula durarà" ${ }^{33}$. Era el Consell de Cent el encargado de escogerlos, aunque, en caso de creerlo conveniente, podía derivar esta función ${ }^{34}$. El procedimiento para hacerlo, tal como se explica en 1452, era muy parecido al que se seguía con los administradores de la Taula: en primer lugar, el escribano del Consell leía

\footnotetext{
28 Vicens Vives, Ferran II i la ciutat de Barcelona, p. 68.

29 Feliu i Montfort, Els primers llibres de la Taula de Canvi, pp. 44-45.

Feliu i Montfort, Els primers llibres de la Taula de Canvi, p. 46.

$A H C B, 1 B . X I$, Clavaria, 37, f. 131v, 28-III-1414.

$A H C B, 1 B . X I$, Clavaria, 63, f. 76r, 1-II-1446.

$A H C B$, 1B.XI, Clavaria, 55, f. 99v, 20-V-1440.

34 En abril de 1452, después de la muerte de Guillem Esteve, encargado del manual de la Taula de Canvi, el Consell de Cent derivó la elección de su sucesor a los consellers y a una asamblea de treinta jurados elegida a suertes ( $A H C B$, 1B.II, Deliberacions, ff. 158r-159r, 25-IV-1452).
} 
un memorial confeccionado por los consellers donde constaban los nombres de algunos notarios de la ciudad, que la asamblea procedía a aprobar. Seguidamente, tanto los consellers como los jurados del Consell escribían el nombre del candidato que consideraban más adecuado en un trozo de papel, que introducían en una caja. Una vez todos habían votado, se hacía el escrutinio correspondiente y se publicaba el resultado.

Del mismo modo que ocurrió con los administradores, el privilegio de 1498 alteró el sistema mediante el cual los escribanos de la Taula eran elegidos. Así, con la implantación de la insaculación se estableció que el encargado del libro corrible y el del de depósitos se extraerían de la bolsa de los consellers cuartos, igual que el denominado caixer del compte ordinari de la Ciutat y uno de los oïdors de comptes de la Taula. En cambio, el responsable del libro manual saldría, junto al escribano mayor del Consell, el síndic y el sotssíndic, de una bolsa elocuentemente llamada arxiver, escrivà major $i$ síndic ${ }^{35}$. Como puede suponerse, el principal cometido de los escribanos de la Taula de Canvi era ocuparse del libro que tenían adjudicado, ya fuera el corriente, el manual o el de depósitos, sin los cuales la Taula no podía funcionar. ¿En qué consistía cada uno de ellos? Tanto el libro corrible como el de depósitos formaban parte de los llamados libros mayores de la Taula. En palabras de Feliu, "els [llibres] majors corrents són els normals en qualsevol comptabilitat", mientras que "els majors de dipòsits corresponen a la gestió dels dipòsits condicionats (a solta)" ${ }^{36}$. Por lo que respecta al manual, era simplemente el diario de las operaciones efectuadas en la Taula. Más allá de esta importante función, Feliu apunta que quizás uno de estos adjuntos era el encargado de hacer las funciones de cajero, pero la documentación consultada no permite confirmar ni rebatir esta hipótesis ${ }^{37}$.

Los salarios percibidos por los escribanos a lo largo del siglo XV fueron modificados sustancialmente en distintas ocasiones. Desde 1401, cuando el único escribano mencionado en el segundo libro de clavaria de ese año, Jaume Cardona, recibió 2.000 s.b. anuales, hasta 1442 los cambios fueron más que notables, como puede observarse en la Tabla 1.

A la vista de las marcadas oscilaciones que sufrieron los salarios de los escribanos durante los primeros años de vida de la Taula de Canvi, parece que durante este período habría ciertos problemas para fijar exactamente cuáles eran las retribuciones adecuadas para algunos de los oficiales que trabajaban en ella. De hecho, las cantidades más altas que

\footnotetext{
35 Vicens Vives, Ferran II i la ciutat de Barcelona, p. 295.

36 Como el mismo Feliu señala, un asiento se inscribía en el libro de depósitos si el capital al que hacía referencia no estaba disponible (Feliu i Montfort, Els primers llibres de la Taula de Canvi, p. 16).

37 Feliu i Montfort, Els primers llibres de la Taula de Canvi, p. 45. La presencia en la Taula de Canvi de los tres libros y el juego que se establecía entre ellos evocan la contabilidad por partida doble. Tratándose de una institución de carácter público, pero evidentemente muy influenciada por el modelo privado y, recordémoslo, dirigida siempre por un mercader, este hecho no resultaría tan sorprendente. Sin embargo, según Francisco Mayordomo, que tiene en cuenta los requisitos determinados por Raymond de Roover para considerar que se aplica el método de la partida doble, el utilizado por la Taula barcelonesa era incompleto (Mayordomo García-Chicote, La Taula de Canvis, p. 62). En cambio, Feliu opina en su obra más reciente, después de un pormenorizado análisis del concepto de la partida doble, que "els primers llibres de la Taula de Canvi acompleixen, amb petites mancances, les condicions exigides perquè una comptabilitat pugui ser considerada de partida doble" (Feliu i Montfort, Els primers llibres de la Taula de Canvi, pp. 69-76).
} 
TABLA 1.

Salarios de los escribanos de la Taula de Canvi entre 1401 y 1442.

\begin{tabular}{cccc}
\hline & Primer escribano & Segundo escribano & Tercer escribano $^{38}$ \\
\hline $\mathbf{1 4 0 1}$ & 2.000 s.b. & - & - \\
\hline $\mathbf{1 4 0 3}$ & 1.400 s.b. & 1.100 s.b. & - \\
\hline $\mathbf{1 4 0 9}$ & 1.100 s.b. & 1.100 s.b. & - \\
\hline $\mathbf{1 4 1 0}$ & 2.800 s.b. & 1.100 s.b. & - \\
\hline $\mathbf{1 4 1 4}$ & 4.300 s.b. & 800 s.b. & 1.200 s.b. \\
$\mathbf{1 4 1 9}$ & 4.300 s.b. & 800 s.b. & 1.200 s.b. \\
$\mathbf{1 4 3 4}$ & 4.300 s.b. & 800 s.b. & 1.200 s.b. \\
\hline $\mathbf{1 4 4 2}$ & 2.600 s.b. & 800 s.b. & 800 s.b. \\
\hline
\end{tabular}

encontramos en 1414 y 1442 las recibió durante todo ese tiempo una única persona, Antoni Cases, y parece que no fue hasta que este se jubiló, hacia 1442, que los salarios de los tres escribanos se equilibraron considerablemente ${ }^{39}$.

Fue en algún momento entre 1442 y 1446 cuando se estableció claramente de qué se ocupaba cada uno de los tres notarios que trabajaban en la Taula, o por lo menos empezó a plasmarse en las fuentes municipales. Así, ya en 1446 se observa que el responsable del libro corrible recibía 2.200 s.b., el del manual 2.000 s.b. y el del libro de depósitos 800 s.b. anuales, cantidades que aparecen ligeramente modificadas dos años después, cuando el regidor del libro corrible recibía $2.600 \mathrm{s.b}{ }^{40}$.

Ahora bien, no todo el mundo estaba de acuerdo con estos salarios. En noviembre de 1448 el encargado del manual presentó al Consell una petición junto a un pesador, en la cual solicitaban un aumento de sueldo ${ }^{41}$. El escribano, Guillem Esteve, nos ofrece en su súplica una interesante explicación sobre qué entendía él que era el libro del que se ocupaba día tras día:

"lo qual manual és cap e fundament de la dita Taula, e lo qual és de gran importància e vexació d'enteniment, com en aquell se haien exprimir totes condicions,

\footnotetext{
$38 \mathrm{Ni}$ en 1414 ni en 1434 hubo un salario cobrado específicamente por un tercer escribano, sino que fue el primer escribano, el denominado regidor de cuentas, quién recibió un sueldo en el que se incluían los 1.200 s.b. que cobraba un tal Ramon Santmartí, ayudante de los escribanos de la Taula.

39 De hecho, Joan Pasqual, sucesor de Antoni Cases, recibiría solo 2.200 s.b. mientras Cases viviera, de modo que únicamente tras la muerte de este pasaría a percibir los 2.600 s.b. pertinentes. La cantidad restante formaba parte de la pensión que Cases recibía como compensación por los servicios prestados a la ciudad. En la misma situación se encontraba otro de los escribanos, Jaume Tutxó, que sustituía a Joan Ramis, y que en vida de este solo recibiría 600 de los 800 s.b. que teóricamente tenía asignados. Sin embargo, Pasqual nunca llegó a cobrar su sueldo completo, ya que fue uno de los protagonistas de los "desórdenes y abusos" que sacudieron la Taula meses después, motivo por el cual fue despedido ( $A H C B$, 1B.II, Deliberacions, ff. 11r-11v, 19-XI-1442, y ff. 12v-13v, 20-XI-1442).

$40 A H C B$, 1B.XI, Clavaria, 63, f. 76r, 1-II-1446; $A H C B$, 1B.XI, Clavaria, 64, f. 82v, 8-VIII-1448.

${ }^{41} A H C B$, 1B.II, Deliberacions, 5, ff. 54r-54v, 14-XI-1448.
} 
empares, cancel·lacions de empares, testaments, donacions, procuracions, manaments e tota altra natura de contractes a fi que lo deliurament de les peccúnies que's fan en la dita Taula sien fetes legítimament e segons se pertany a indempnitat de la Taula, lo qual càrrec, com vostres savieses poden pensar, no és poch"42.

Más allá de la evidente importancia que atribuía a su cargo, Esteve argumentaba que en los últimos tiempos tenía más trabajo como consecuencia de las nuevas ordenanzas relativas a la Taula de Canvi, que a efectos prácticos suponían que en aquel momento no hubiera "altra taula sinó la Taula de la ciutat". Y añadía, además, que era "privat per ordinació de tota natura de affers e de libertat, a la qual or no és equiparable" ${ }^{43}$. Por todo ello, pedía un aumento de sueldo, que se le concedió añadiendo 200 s.b. a los 2.000 que ya recibía ${ }^{44}$.

El año siguiente fue Joan Guimerà, encargado del libro corriente, quien solicitó al Consell que se le concediera un ayudante, ya que "per los grans affers qui són en la dita Taula e per indisposició de sa persona, no abasta a donar lo compliment que deu a la dita Taula, e ha dupte que per rahó del gran treball no li·n vingue alguna malaltia, segons ja pochs dies ha passats ne ha haüda" ${ }^{45}$. El Consell, considerando que su sueldo ya se había aumentado anteriormente, acordó que antes de tomar una decisión se entrevistaría con él para preguntarle si tenía intención de pagar parte del salario de su posible ayudante. Tres meses después, una vez obtenida la información deseada, la asamblea, "attesa la bondat e sufficiència" de Guimerà, así como "la gran voluntat que ha al ben públich de la dita ciutat, en tant que no se'n trobaria altre de què posquessin millorar", propuso darle entre 300 y 400 s.b. anuales que tendría que emplear en pagar el salario de un ayudante, a quien él mismo se encargaría de escoger y del cual sería responsable ${ }^{46}$. Pero el aumento no debió materializarse, ya que en diciembre de 1449 Guimerà volvió a presentar una petición donde reiteraba que, teniendo en cuenta el trabajo que había y el que preveía que habría en la Taula, la experiencia le advertía que él solo no podría hacerle frente, motivo por el cual necesitaba un ayudante que "pogués continuar e scriure en lo dit libre". Esta vez proponía que, "attès que lo dit aiudant irà a tot son càrrech e lo seu salari no és tal que no l'haie ben necessari a sostentació de sa vida", la ciudad le diera alguna ayuda

\footnotetext{
$42 A H C B$, 1B.II, Deliberacions, 5, ff. 68r-69r, 18-XI-1448.

43 Esteve añadía a continuación, quizás para impresionar a los jurados del Consell, el dicho latino, que había traducido de forma más o menos libre, "non bene pro toto libertas venditur auro".

44 Tal como se irá viendo a lo largo de este estudio, durante esos años fueron frecuentes las peticiones de aumento de sueldo, y se tendió a acceder a las súplicas quizás porque eran realmente justas. Aún así, siempre se puntualizó que era una gracia otorgada a título personal, de modo que los sucesores de los que habían sido beneficiados recibirían el salario anterior a la petición.

$45 A H C B$, 1B.II, Deliberacions, 5, ff. 152v-154r, 9-VII-1449.

$46 A H C B$, 1B.II, Deliberacions, 6, ff. 2v-3v, 31-X-1449.
} 
pecuniaria $^{47}$. Finalmente, el marzo siguiente el Consell acordó concederle 400 s.b. anuales, destinados únicamente al salario del ayudante ${ }^{48}$.

Quizás los problemas de salud a que se refería Guimerà eran más importantes de lo que podía parecer, porque en 1451 murió y tuvo que escogerse un nuevo responsable del libro corrible de la Taula de Canvi, el salario del cual se rebajó de nuevo a 2.200 s.b. ${ }^{49}$. Una situación similar fue la que vivió el sucesor del mencionado Guillem Esteve en 1452, siendo fijado su sueldo como responsable del manual en los 2.000 s.b. anuales que recibía dicho Esteve antes de $1448^{50}$.

Así pues, los salarios de los tres escribanos a las puertas de la guerra civil catalana eran de 2.200 s.b. para el encargado del libro corriente, 2.000 para el del manual, y 1.600 para el de depósitos. Estas retribuciones no fueron alteradas hasta la ya mencionada reforma de 1489, cuando el responsable del libro corrible pasó a cobrar 2.000 s.b. y el del de depósitos 1.500, permaneciendo inalterado únicamente el sueldo del notario a cargo del manual ${ }^{51}$.

\subsection{Los pesadores y reconocedores}

Los pesadores y reconocedores de monedas de la Taula de Canvi han sido agrupados en un mismo apartado no únicamente por su evidente afinidad laboral, sino también porque a menudo resulta difícil distinguirlos, ya que el apelativo usado para designarlos parece fácilmente intercambiable ${ }^{52}$.

A pesar de que aparentemente en 1403 todavía no había ninguno, según Feliu el cargo de pesador de monedas habría aparecido antes de 1408, y en el libro de clavaria del segundo semestre de 1409 encontramos dos, número que se mantuvo inalterable hasta el final del período estudiado ${ }^{53}$. Únicamente en 1466, ante la situación delicada tanto de la Taula de Canvi como de las finanzas municipales, el Consell consideró durante un tiempo la posibilidad de eliminar uno. Después que el Trentenari derivara el asunto a la asamblea general, y esta lo devolviera de nuevo al Consell de Trenta, se acordó escuchar en primer lugar el parecer de aquellos que trabajaban codo con codo con los que tenían el cargo en cuestión: los administradores de la Taula ${ }^{54}$. Una vez Pere Joan

\footnotetext{
$47 A H C B$, 1B.II, Deliberacions, 6, ff. 31v-32r, 13-XII-1449.

$48 A H C B$, 1B.II, Deliberacions, 6, ff. 69r-69v, 3-III-1450.

$49 A H C B$, 1B.II, Deliberacions, 7, ff. 113r-113v, 23-XI-1451, y ff. 115v-116v, 24-XI-1451.

$50 A H C B, 1 B . I I$, Deliberacions, 7, ff. 158r-159r, 25-IV-1452.

51 Vicens Vives, Ferran II $i$ la ciutat de Barcelona, p. 68. Vicens solo menciona los nombres de los oficiales, pero no sus cargos. Sin embargo, la consulta de otras fuentes permite conocer qué oficio tenía cada uno de ellos.

52 En 1466, por ejemplo, en el Consell se discutió la posibilidad de "remoure e suspendre un dels pesador o regonexedor de les monedes de la Taula de Canvi", mientras que tres meses más tarde, cuando los ministros y oficiales de la Taula de Canvi prestaron juramento, uno de ellos fue nombrado pesador y el otro reconocedor ( $A H C B$, 1B.II, Deliberacions, 17, f. 146v, 15-XI-1466, y f. 180r, 3-II-1467).

53 Feliu i Montfort, Els primers llibres de la Taula de Canvi, p. 45, n. 33; AHCB, 1B.XI, Clavaria, 33, f. 111r, 19-VII-1409.

${ }^{54} A H C B$, 1B.II, Deliberacions, 17, ff. 144v-145r, 14-XI-1466, y ff. 146v-147r, 15-XI-1466.
} 
Serra, uno de los taulers, hubo dado su opinión, el Consell decidió mantener los pesadores como estaban, si bien rebajando el salario de ambos y obligándolos a ayudar al encargado del libro de depósitos ${ }^{55}$.

Por lo que respecta a su elección, parece que esta era llevada a cabo por el Trentenari, y aquellos que resultaban designados ejercían el cargo teóricamente de por vida. Sin embargo, durante el siglo XV hubo por lo menos una notoria excepción. En 1476 se descubrió que Pere Morer, pesador desde hacía más de diez años, había tomado entre 44.000 y 46.000 s.b. de la Taula de Canvi para invertirlos en sus propios negocios ${ }^{56}$. Menos de veinte días después, considerando que aquello era un "nephandíssim crim contra la cosa pública e digna de grandíssima punició”, y estando el caso en manos del gobernador, Morer fue retirado del cargo y se escogió alguien para sustituirlo ${ }^{57}$.

La tarea que tenían que llevar a cabo los pesadores y reconocedores de moneda era clara: comprobar las monedas de oro y de plata que se ingresaban y se pagaban en la Taula de Canvi. A cambio, recibían una remuneración que fue variando a lo largo del siglo XV, como puede observarse para los años 1409-1427 en la Tabla 2.

TABLA 2.

Salarios de los pesadores y reconocedores entre 1409 y 1427.

\begin{tabular}{lcc}
\hline & Primer pesador & Segundo pesador $^{58}$ \\
\hline $\mathbf{1 4 0 9}$ & 1.200 s.b. & 1.200 s.b. \\
$\mathbf{1 4 1 4}$ & 1.200 s.b. & 600 s.b. \\
$\mathbf{1 4 1 7}$ & 1.200 s.b. & 1.000 s.b. \\
$\mathbf{1 4 2 7}$ & 1.200 s.b. & 1.200 s.b. \\
\hline
\end{tabular}

Parte de la información relativa a los salarios la conocemos gracias a la petición realizada en 1445 por Pere Ferrer al Consell con toques ciertamente dramáticos ${ }^{59}$. De hecho, la súplica de Ferrer es suficientemente interesante como para aludir a ella brevemente. Según él mismo decía, hacía veintiocho años que ejercía de reconocedor de monedas de la Taula de Canvi, pero aunque el servicio que había prestado hasta entonces podía considerarse "molt útil, experiència demostrant, a la dita Taula", para él particularmente había resultado "molt dampnós". El motivo era que antes de aceptar dicho cargo, él "vivia opulent e ab menys ànsies que vuy no fa" ejerciendo de cambista. Después, sin embargo, y a pesar de las promesas que se le habían hecho respecto al oficio que tenía desde 1417 , le fue asignado un salario "axí estret que en alguna manera no basta a la

\footnotetext{
$A H C B$, 1B.II, Deliberacions, 17, ff. 151r-152r, 26-XI-1466.

$56 A H C B$, 1B.II, Deliberacions, 23, ff. 23v-31r, 2-IV-1476. Este incidente es narrado en BRUNIQUER I RIERA, Rúbriques de Bruniquer, p. 79.

$57 A H C B$, 1B.II, Deliberacions, 23, ff. 32r-32v, 20-IV-1476.

58 Algunos años el aquí llamado segundo pesador es identificado como reconocedor de monedas.

59 AHCB, 1B.II, Deliberacions, 3, ff. 133v-135r, 22-VI-1445.
} 
despesa sua ne sustentació de sa casa". Por esta razón, en distintas ocasiones había ofrecido su renuncia para así intentar "procurar sa vida en altra manera", pero se la habían rechazado, dándole de nuevo vanas esperanzas. A todo esto Ferrer añadía las consecuencias de las nuevas leyes y ordenanzas que se habían hecho para la Taula de Canvi, que consideraba "molt restrictives e prohibitives als honorables regidors e als officials e ministres de la dita Taula". Concretamente, afirmaba que dichas normas tenían que ser "tengudes a la ungla", de modo que "tot lícit emolument per la justa suor dels dits officials e ministres és a ells interdit e inhibit". En resumen: por todas estas razones, Ferrer pedía un aumento de sueldo. No podemos saber cuánta verdad había en las palabras de Pere Ferrer respecto a su situación personal, pero debía ser suficiente como para conmover a los jurados del Consell, ya que aceptaron que el pesador recibiera 800 s.b. más, llegando así a los 2.000 s.b. anuales. Eso sí, puntualizaban que Ferrer cobraría este salario únicamente por el buen servicio que había hecho a la ciudad durante mucho tiempo, de modo que su sucesor recibiría los 1.200 s.b. habituales.

Es posible que fuera el ejemplo de Ferrer lo que inspiró dos años después al pesador Guillem de Dons a hacer la ya mencionada petición de aumento de sueldo junto al escribano Guillem Esteve ${ }^{60}$. En este caso, el argumento principal era que, vista la cantidad de trabajo que tenían, consideraban sus salarios insuficientes. Así, Guillem de Dons, igual que Esteve, argumentaba que las dos recientes ordenanzas ya citadas habían provocado que los movimientos en el banco se duplicaran, de modo que Dons tenía que "pesar, comptar e regonèxer e deliurar moltes més quantitats de monedes que no solia", $\mathrm{y}$, además, escribir en dos cuadernos, uno llamado "de rebudes" y el otro "de record", las monedas depositadas en la Taula, cosa que antes no se hacía ${ }^{61}$. Escuchados sus motivos, el Consell accedió a añadir 400 s.b. a los 1.200 s.b. que ya recibía, aunque de nuevo se dejó anotado que sus sucesores no contarían con este aumento.

Doce años después la situación seguía siendo la misma, pero en algún momento entre 1459 y 1462, posiblemente a raíz de la dimisión o muerte de Pere Ferrer, los salarios del pesador y del reconocedor se igualaron una vez más, esta vez a 2.000 s.b. ${ }^{62}$. Estos sueldos se mantuvieron durante poco tiempo, ya que en 1466, "per la necessitat en la qual la present ciutat vuy se trobe", los dos se redujeron a 1.600 s.b. anuales ${ }^{63}$. La última noticia que por ahora puedo dar sobre el salario de los pesadores y reconocedores de monedas es que en el redreç de 1489 se decidió mantener intacto el salario del pesador, mientras que el del reconocedor pasó de 1.600 a 1.500 s.b. ${ }^{64}$.

${ }^{60} A H C B$, 1B.II, Deliberacions, 5, ff. 54r-54v, 14-XI-1448.

61 Como el mismo Dons explicaba, según las nuevas ordenanzas ningún cambista podía librar dinero si previamente no se había asegurado, y todos los cambios que se hiciesen en Barcelona tenían que hacerse en la Taula de Canvi ( $A H C B$, 1B.II, Deliberacions, 5, ff. 69r-70r, 18-XI-1448).

62 En noviembre de 1459, Guillem de Dons todavía cobró a razón de 1.600 s.b. anuales, mientras que en agosto de 1462 lo hizo a razón de 2.000 s.b. (AHCB, 1B.XI, Clavaria, 72, f. 95v, 10-XI-1459; $A H C B$, 1B.XI, Clavaria, 75, f. 80v, 25-VIII-1462).

$63 A H C B$, 1B.II, Deliberacions, 17, ff. 151r-152r, 26-XI-1466.

64 Vicens Vives, Ferran II $i$ la ciutat de Barcelona, p. 68. Igual que en el caso de los escribanos, Vicens solo menciona los nombres de los oficiales, pero no sus cargos. Sin embargo, sabemos por los registros 


\subsection{Los servidores y el "bastaix"}

En el grupo heterogéneo formado por los servidores y el bastaix (faquín) de la Taula de Canvi encontramos de hecho tres cargos distintos. En primer lugar, el servidor de la Taula propiamente dicho; en segundo, otro servidor que trabajaba también con el clavario y los racionales municipales, y por último un bastaix, o, como a menudo se le llama, encargado de transportar las monedas y libros de la Taula de Canvi.

Según Feliu, la Taula hubiera tenido que contar desde su aparición con alguien que hiciera las funciones de lo que el autor denomina "andador", que equivaldría al dicho servidor, y de bastaix $^{65}$. Tal como este autor señala, el primero sería creado más adelante, si bien parece que inicialmente sus tareas correspondían al escribano encargado del libro manual, aunque los ejemplos documentados por Feliu muestran que a efectos prácticos las llevaba a cabo cualquier persona considerada de confianza. Por lo que respecta al bastaix, Feliu comenta que aunque su trabajo lo podría haber realizado cualquier empleado municipal, "semblaria més normal que es comptés amb una persona present a la Taula per a qualsevol encàrrec o contingència". Lo único cierto es que los tres cargos aparecen bastante tarde en los libros de clavaria. Así, el servidor de la Taula se documenta por primera vez en algún momento entre 1440 y 1442, si bien fue probablemente a finales de 1442 cuando se reguló su presencia continua en el banco ${ }^{66}$. Por lo que respecta al segundo servidor, que trabajaba también con los racionales y el clavario, debió aparecer entre 1446 y 144867. El caso del bastaix es más peculiar, ya que la primera referencia que he podido encontrar es en una anotación del registro de Deliberacions del año 1452, en la cual se comenta una petición hecha por Miquel Trobat, según el cual hacía quince años que trabajaba de bastaix en la Taula de Canvi -por lo tanto, desde 1437-68.Ahora bien, en los libros de clavaria entre 1441 y 1451 consultados no aparece ningún pago de salario a Trobat, de lo que podría inferirse que el cargo no fue creado específicamente hasta algún momento entre 1451 y 1457, año en el cual sí que aparece una retribución concreta para dicho cargo y se reguló el pago del bastaix $x^{69}$. De igual modo que los escribanos y los pesadores y reconocedores de moneda, tanto los servidores como el bastaix de la Taula de Canvi eran escogidos vitaliciamente. Por

de Clavaria y de Deliberacions que ese año Nicolau Julià y Nicolau Boada ejercían de pesadores y reconocedores de monedas de la Taula de Canvi.

65 Feliu i Montfort, Els primers llibres de la Taula de Canvi, p. 45.

${ }_{66} A H C B, 1 B . X I$, Clavaria, 60, f. 104r, 29-XI-1442. En este asiento se indica que el servidor cobró por el trabajo que había realizado durante un año, según se acordó en el Consell nueve días antes. Teniendo en cuenta que en el primer libro de clavaria de 1440 no se le menciona y en el primero de 1446 ya aparece cobrando un salario regular, probablemente este fue el inicio del servidor como cargo institucionalizado.

67 El primer pago que he documentado a un servidor de la Taula de Canvi, de los racionales y del clavario se encuentra en $A H C B, 1 B . X I$, Clavaria, 64, f. 123r, 9-I-1449. En el anterior libro conservado, el del primer semestre de 1446, no hay ninguno.

${ }_{68} A H C B, 1 \mathrm{~B} . \mathrm{II}$, Deliberacions, 7, ff. 199r-199v, 13-X-1452.

${ }_{69} A H C B, 1 B . X I$, Clavaria, 70, f. 85v, 20-X-1457. Probablemente, el salario del bastaix fue regulado precisamente a raíz de la petición presentada por Trobat en 1452 . 
esta razón son pocas las elecciones documentadas de estos cargos. No obstante, sabemos que en 1456 fue el Consell de Trenta el encargado de designar a Guillem Ramon de Santamaria como servidor de los racionales, el clavario y la Taula una vez muerto su antecesor $^{70}$. El procedimiento seguido fue el habitual: en primer lugar, se presentó un memorial confeccionado por los consellers con los nombres de las personas que ellos consideraban adecuadas, para que fuera aprobado o bien modificado por la asamblea. Seguidamente, el Trentenari y los consellers procedieron a votar mediante cédulas de papel introducidas en una caja.

Seguramente se actuó de un modo similar en noviembre de 1463, cuando Joan Martorell, servidor de la Taula, dimitió aduciendo su edad avanzada ${ }^{71}$. El Consell de Trenta rápidamente eligió un substituto, que sin embargo no cobraría el salario que en principio le correspondía, ya que este se mantendría en manos de Martorell hasta su muerte ${ }^{72}$. El mismo procedimiento se siguió en 1468, cuando el citado Miquel Trobat, bastaix de la Taula, ya mayor, decidió que Guillem Deguant, también bastaix y que ya estaba bajo sus órdenes, lo remplazara. También en este caso Deguant empezaría a percibir su sueldo a partir de la defunción de Trobat $^{73}$. El año 1476 fue Guillem Ramon de Santamaria, anciano y enfermo de gota, quien pactó la cesión de su cargo a cambio de mantener 500 s.b. anuales de los 820 s.b. que constituían su salario ${ }^{74}$.

No siempre son claras las funciones que se asociaban a estos cargos. Feliu define la figura del andador como la persona que iba a casa de aquellos que lo pedían para recibir algún ingreso y trasladarlo a la Taula, o bien para llevar dinero a personas que no podían ir personalmente al banco ${ }^{75}$. Esta explicación coincide bastante con la que aparece en los libros de clavaria, donde se dice que se paga el salario del servidor de la Taula por haber ayudado "axí en demanar, exhigir e executar diversos deutes qui són deguts per diverses persones a la dita ciutat per rahó de imposicions, com encara en tot lo exercici

\footnotetext{
$70 A H C B$, 1B.II, Deliberacions, 10, ff. 100v-101v, 20-V-1456.

$71 A H C B$, 1B.II, Deliberacions, 16, f. 53v, 4-XI-1463.

72 Joan Sòcies, designado sucesor de Martorell, no tuvo que esperar demasiado para empezar a percibir un sueldo por su flamante cargo: en mayo de 1464 ya recibió 200 s.b. en concepto del salario de tres meses iniciados el 10 de febrero anterior, una vez muerto su antecesor ( $A H C B$, 1B.XI, Clavaria, 76, f. 85r, 11-V-1464).

$73 A H C B$, 1B.II, Deliberacions, 18, f. 120r, 3-VIII-1468. Miquel siguió percibiendo su salario hasta abril de 1472, cuando su viuda, Caterina, lo cobró por última vez ( $A H C B, 1 B$.XI, Clavaria, 87, f. 136v, 16-IV-1472). En enero de 1477 fue Guillem Deguant quien presentó al Consell su renuncia como bastaix de la Taula, argumentando que se había "fet vell en lo servey del dit exercici", motivo por el cual los taulers habían aceptado hacía ya un tiempo que tuviera un ayudante, Francí Dona ( $A H C B, 1 B$.II, Deliberacions, 23, ff. 105v-106v, 21-I-1477). A pesar de que el Trentenari aceptó su “jubilación”, ignoró la petición de Guillem de mantener el salario de bastaix de forma vitalicia, para así tener "forma de viure en se vellesa", cosa que finalmente se le concedió unos meses después ( $A H C B, 1 B . I I$, Deliberacions, 23, ff. 173v-175r, 25-XI-1477). ${ }^{74}$ El Consell aprobó la petición de Santamaria, diciendo que no era "cosa digne que attès lo dit servey en se vellesa sia del tot frustrat del dit salari, ço que la ciutat nuncha ha acustumat, ans tostemps és stat per aquella praticat que los servidors de aquella, venint a vellesa e no podent servir, han haüt tal soccorriment e salari que rehonablement han passada lur vida" ( $A H C B$, 1B.II, Deliberacions, 23, ff. 75v-77v, 27-XI-1476).

75 Feliu i Montfort, Els primers llibres de la Taula de Canvi, p. 45.
} 
de la dita Taula" ${ }^{76}$. Si nos fijamos ahora en el servidor que trabajaba también para el clavario y los racionales, vemos que sus tareas son calificadas como "deservint en la Taula del Cambi de la ciutat de Barchelona e en servir lo ofici dels racionals e clavari de aquella, exhigint e fahent axecutar tots aquells que deuen res a la dita ciutat, axí per rahó de imposicions com en altra manera" "77. Parece, pues, que ambos servidores tenían cometidos bastante parecidos. A pesar de ello, es posible que el segundo tuviera un carácter más representativo, ya que cada Navidad recibía además de su salario habitual 100 s.b. que debía destinar a sus vestiduras. Por lo que respecta al bastaix, identificar sus obligaciones resulta más sencillo: era la persona encarga de los traslados diarios de la caja y los libros de la Taula de la casa del administrador a la Llotja ${ }^{78}$.

Finalmente, por lo que respecta a la cuantía de la retribución, ya se ha comentado que no es hasta ya avanzado el siglo XV cuando encontramos las primeras remuneraciones de estos cargos. En los libros de clavaria vemos que en 1442 el servidor de la Taula recibía 660 s.b., cantidad que cuatro años después ya había aumentado hasta los 800 s.b. anuales ${ }^{79}$. La primera mención al sueldo del servidor compartido con el oficio de los racionales y el clavario es de 1448, cuando tenía adjudicados 720 s.b. de salario ordinario y 100 s.b. para su ropa ${ }^{80}$, y la del bastaix, como se ha dicho anteriormente, de 1457, cuando cobraba 600 s.b. por año ${ }^{81}$. Ahora bien, es importante recordar una vez más que en 1452 el bastaix Miquel Trobat presentó una petición al Consell, en la cual se quejaba del hecho que hacía quince años que ejercía ese oficio "e per sobre dels grans càrrechs que algunes vegades portave" se había "trenchat", siendo este el motivo que lo había empujado a contratar a un ayudante, que él mismo pagaba ${ }^{82}$. Por lo tanto, siendo incapaz de cargar con la caja y los libros como de él se esperaba, pero teniendo en cuenta la necesaria ayuda que prestaba a los contadores de monedas, solicitaba un salario decente para "provehir si mateix, sa muller e sos infants". Al cabo de once días, los consellers y los administradores de la Taula acordaron que se pagaran a Trobat 600 s.b. por año, aunque no a sus sucesores, y al otro bastaix 20 florines ( 220 s.b.) a cambio de que cargara la caja. La disposición sobre el salario del bastaix no se cumplió, ya que, muerto Trobat en 1472, su sucesor siguió recibiendo 600 s.b. anuales ${ }^{83}$. De hecho, los sueldos de los tres cargos se mantuvieron inalterados hasta la gran reforma de 1489. A partir de ese momento, el servidor de la Taula pasó de ganar 800 s.b. a recibir 600 s.b., el segundo servidor de 820 a 700 s.b. y el bastaix de 600 a 500 s.b. ${ }^{84}$.

\footnotetext{
$76 A H C B, 1 B . X I$, Clavaria, 63, f. 81v, 3-IV-1446.

$77 A H B C, 1 B . X I$, Clavaria, 76, f. 80v, 4-IV-1464.

78 Feliu i Montfort, Els primers llibres de la Taula de Canvi, p. 45.

$79 A H C B$, 1B.XI, Clavaria, 60, f. 104r, 29-XI-1442; $A H C B$, 1B.XI, Clavaria, 63, f. 81v, 4-III-1446.

$A H C B, 1 B . X I$, Clavaria, 64, f. 123r, 9-I-1449.

$A H C B$, 1B.XI, Clavaria, 70, f. 85v, 20-X-1457.

$A H C B$, 1B.II, Deliberacions, 7, ff. 199r-199v, 13-X-1452.

83 La disposición tomada a raíz de la ya mencionada jubilación de Trobat en 1468 parece indicar que, en realidad, tampoco entonces se consideró hacer valer el acuerdo al que se había llegado en 1452.

84 Vicens Vives, Ferran II i la ciutat de Barcelona, pp. 69-70. En el caso de los servidores, Vicens no nombra los cargos, sino las personas que los ejercían: Joan Sòcies, servidor de la Taula de Canvi, y Gaspar Peraller, servidor de la Taula, los racionales y el clavario.
} 


\section{Los oïdors de comptes}

Los oïdors de comptes de la Taula de Canvi, llamados también encargados del archivo de los libros de la Taula o simplemente regidores de dichos libros, se documentan por lo menos desde noviembre de $1410^{85}$.

Aunque dicho año aparecen tres personas encargándose de la revisión de las cuentas del banco, parece que el suyo fue un nombramiento de carácter puntual, ya que únicamente tenían que auditar los libros de una administración. Cuando a partir de, como tarde, finales de 1413, se documenta el cargo como tal, se observa que fue ocupado únicamente por una persona, situación que se mantuvo hasta $1458^{86}$. Así pues, no fue hasta abril de 1458 que el Consell de Cent aprobó que se eligieran dos, "attesos los grans affers qui són creschuts en la dita Taula en diverses maneres" ${ }^{87}$. Sin embargo, este segundo oïdor no se mantuvo demasiado tiempo. En 1466, la asamblea puso en duda la necesidad de contar con los dos en un contexto en que las finanzas municipales no pasaban por su mejor momento, y finalmente optó por prescindir de uno de ellos ${ }^{88}$. No obstante, se estableció que el que permanecería en el cargo, aunque no disfrutara de ningún aumento de sueldo, podría contar con la colaboración de algún joven ayudante. Esta fue la situación del oficio hasta 1474, cuando después de la muerte del único oïdor, Bartomeu Montcofa, el Trentenari derivó al Consell de Cent la elección de uno nuevo ${ }^{89}$. El mismo día de la asamblea general, los consellers propusieron al Consell de Trenta que se sugiriera al de Cent la posibilidad de elegir dos ö̈dors en lugar de uno solo, alegando que el ayudante que se había asociado al cargo desde 1466 no era "stret a la ciutat de tenir secrets e altres honestats, e quescun dia se poria mudar, e axí los secrets de la Taula porien venir a persones indiscretes" ${ }^{90}$. Así, finalmente el Consell de Cent determinó que, habida cuenta la cantidad de trabajo, el oficio del archivo contara de nuevo con dos oïdors ${ }^{91}$.

El personal del archivo de la Taula era escogido por el Consell de Cent de modo similar a como se hacía en los casos de los cargos ya explicados, esto es, mediante

\footnotetext{
85 En el libro del clavario del segundo semestre de 1410 se dice que se pagó a Berenguer Seiol, Gabriel Ballester y Bernat Safont por "veure e regonèxer, exeminar e discutir los libres del regiment e administració de la Taula del Cambi” del bienio 1407-1408 (AHCB, 1B.XI, Clavaria, 34, f. 131v, 5-XI-1410).

86 En junio de 1414 se pagó el salario del examinador de las cuentas de la Taula, Martí Sarriera, quien tenía dicho cargo desde el día de Santa Lucía de 1413 (AHCB, 1B.XI, Clavaria, 37, f. 134r, 14-VI-1414). $87 A H C B$, 1B.II, Deliberacions, 12, ff. 11v-12v, 25-IV-1458.

88 AHCB, 1B.II, Deliberacions, 17, f. 151r, 26-XI-1466. Sin embargo, con las nuevas ordenanzas de la Taula de Canvi, publicadas al cabo de un año, se le rebajó el salario $(A H C B, 1 B$.II, Deliberacions, 18 , f. 98v, 18-II-1468).

${ }^{89} A H C B$, 1B.II, Deliberacions, 22, ff. 49v-50r, 21-IV-1474.

$90 A H C B$, 1B.II, Deliberacions, 22, f. 51v, 25-IV-1474.

91 AHCB, 1B.II, Deliberacions, 22, ff. 52r-55r, 25-IV-1474. Miquel Ferran, el oüdor suprimido en 1466 y que llevaba ejerciendo el cargo desde 1458, pidió ser uno de los escogidos, pero el Consell de Cent decidió que no tuviera ningún tipo de ventaja respecto a los otros candidatos. Según el recuento de votos, que excepcionalmente encontramos transcrito en el registro de Deliberacions, Ferran quedó cuarto, de modo que finalmente no logró volver al archivo de la Taula.
} 
un memorial confeccionado por los consellers y la posterior votación ${ }^{92}$. Este debió ser el mecanismo utilizado hasta 1498, cuando los auditores de la Taula de Canvi pasaron a formar parte del grupo de oficiales municipales que eran designados por insaculación. Tal como ya se ha señalado al hablar de los escribanos, uno de ellos era extraído de la bolsa de los consellers cuartos, mientras que el otro lo era de otra, llamada de "arxiver, escrivà major i síndic" ${ }^{93}$.

Los ö̈dors se elegían para un período de tiempo no determinado, de modo que de facto solía ser un cargo vitalicio. Pese a todo, durante el período estudiado hubo por lo menos una notoria excepción: la de Bernat de Granollacs, hijo del conocido médico y astrólogo homónimo ${ }^{94}$. Granollacs, ciudadano, había sido elegido oïdor de la Taula de Canvi junto con el notario Miquel Ferran en abril de $1458^{95}$. Al cabo de poco más de un año se vio involucrado en un gran escándalo cuando los consellers se enteraron que un mercader había explicado públicamente que Granollacs compró el oficio del archivo, pagando por él a un ciudadano llamado Pere Vicenç Fabre 1.680 s.b. ${ }^{96}$. Tras la investigación pertinente se pudo confirmar esta información, y se decidió arrestar a todos los involucrados, entre los cuales estaban el propio Granollacs y su padre. Finalmente, el día siguiente el Consell de Cent acordó destituir a Bernat como oïdor de comptes de la Taula, y estableció que ni él ni su progenitor, que había actuado como fiador en la compra fraudulenta del hijo, pudieran tener nunca más un cargo municipal ni formar parte del Consell ${ }^{97}$.

¿De qué se ocupaban exactamente estos oïdors de comptes? Como su nombre indica, eran los encargados de examinar los libros de la Taula de Canvi, tarea que llevaban a cabo comprobando y contrastando "los libres corribles e de depòsits ab los menuals" 98. Por tanto, eran los responsables de hacer lo que en la administración municipal estaba adjudicado a los racionales de la ciudad ${ }^{99}$. Según se observa en los registros de Deliberacions, los ö̈dors tenían que presentar al Consell de Cent una relación de las cuentas de la Taula de Canvi durante una administración concreta, para que así se pudiera firmar a los regidores el documento que los exoneraba y clausuraba definitivamente su ejercicio.

\footnotetext{
92 Así se llevó a cabo, por ejemplo, en abril de 1458 ( $A H C B, 1 B . I I$, Deliberacions, 12, ff. 11v-12v, 25IV-1458).

93 Vicens Vives, Ferran II i la ciutat de Barcelona, p. 295.

94 Bernat de Granollacs sénior es especialmente conocido por ser el autor de un lunario, que gozó de gran popularidad ya durante los últimos años del siglo XV, y por poseer una notable biblioteca (CIFUENTES I Comamala, La ciència en català a l'Edat Mitjana i el Renaixement, pp. 200-201).

$95 A H C B$, 1B.II, Deliberacions, 12, ff. 11v-12v, 25-IV-1458.

$96 A H C B$, 1B.II, Deliberacions, 12, ff. 139v-140v, 15-VI-1449. El mercader, Bartomeu Alcover, explicó que sabía esta información porque había oído como Granollacs lo discutía con un oficial del obispo.

$97 A H C B$, 1B.II, Deliberacions, 12, ff. 140v-141v, 16-VI-1449. Este escándalo ya fue narrado, más detalladamente y enmarcándolo en el conflicto de la Busca y la Biga, por BAtLle i Gallart, "Els Granollacs, metges de Barcelona (segle XV)", pp. 395-97.

$98 A H C B$, 1B.II, Deliberacions, 22, f. 52v, 25-IV-1474.

99 Las ordenanzas de los racionales publicadas en 1466 dicen claramente que estos se encargaban de examinar las cuentas de los impuestos, el clavario y otras administraciones, sin mencionar en ningún momento la Taula de Canvi ( $A H C B$, 1B.IV, Ordinacions, 9, ff. 72v-74r, 20-V-1466).
} 
No necesariamente tenían que hacerlo cada dos años, sino que a veces los encontramos mostrando las cuentas al Consell al cabo de meses o incluso años ${ }^{100}$, coincidiendo en ocasiones la audición correspondiente a dos regidurías distintas ${ }^{101}$. Asimismo, el sistema no siempre funcionaba de forma fluida. En 1459 se decía que los ö̈dors de la Taula de Canvi no habían revisado ninguna cuenta desde 1451 o 1452, cosa que suponía "un gran dan del públic de la dita ciutat", ya que era necesario que la ciudad supiera "quescun any, o almenys quescun bienni, com stà ab la dita Taula, e la gent que ha tenguda e té peccúnias en la dita Taula si deu en aquella o si per inadvertència li és degut". Por estas razones urgía que se encontrase a alguien para ocupar el sitio del recientemente expulsado Bernat de Granollacs ${ }^{102}$.

En cuanto a la retribución, el salario que recibieron los encargados de los libros de la Taula de Canvi también varió sustancialmente a lo largo del siglo XV. En 1414 el ö̈dor ganaba 1.100 s.b., pero solo cinco años después, en 1419, esta cantidad ya era notablemente superior, alcanzando los $1.650 \mathrm{s.b} .{ }^{103}$. Dicho sueldo fue el más alto que los oïdors de la Taula cobraron durante toda la centuria, y parece que se mantuvo hasta la década de $1450^{104}$. Al aprobarse en 1458 la existencia de dos auditores de cuentas se dijo que mantendrían el salario acostumbrado, probablemente los 1.650 s.b. que se sabe que todavía cobraba en $1451^{105}$. Ahora bien, parece que dicha cantidad tenían que repartírsela entre los dos, quedando el sueldo en 850 s.b. para cada uno. Este hecho provocó que pocos meses después ambos ö̈dors presentaran una queja al Consell, en la que clamaban que "sia justa cosa que qui serveix la dita ciutat per aquella dege

${ }^{100}$ En abril de 1433 Martí Sarriera, ö̈dor de comptes de la Taula de Canvi, presentó las cuentas al Consell de Cent de la administración de Tomàs Girona y Joan de Llobera, y en noviembre del mismo año las de la del difunto Bernat Serra y Pere Grau $(A H C B$, 1B.II, Deliberacions, 1, ff. 11v-12r, 25-IV-1433, y ff. 31r-32r, 21-XI-1433).

${ }^{101} A H C B$, 1B.II, Deliberacions, 3, f. 12r, 20-XI-1442.

$102 A H C B$, 1B.II, Deliberacions, 12, ff. 146v-147r, 12-VII-1459, y ff. 147r-148r, 13-VII-1459. Antes de que se llevara a cabo la elección, Bernat de Granollacs sénior hizo llegar a los consellers una carta escrita por Juan II y dirigida al Consell de Cent, en la cual el rey pedía a la asamblea que no tomara ninguna decisión sobre el nuevo oïdor de comptes hasta que él no se encontrara en la ciudad. Sin embargo, los jurados, considerando que "impetrar tals letras era molt mala introducció, car nunque vaccare offici e benefici en la dita ciutat que lo pus petit de aquella no bastàs a traure tals e semblants letras si en aquelles per lo dit Concell era obtemperat", decidieron ignorarla y enviar al rey una carta excusándose por no haber hecho lo que les pedía.

${ }^{103} A H C B$, 1B.XI, Clavaria, 37, f. 134r, 14-VI-1414; $A H C B$, 1B.XI, Clavaria, 38, f. 73v, 14-XII-1419. Los tres examinadores de 1410 recibieron 330 s.b. cada uno en concepto de prorrata, pero dicha cantidad se contemplaba como una retribución extraordinaria y no como salario habitual ( $A H C B, 1 \mathrm{~B}$.XI, Clavaria, 34, f. 131v, 5-XI-1410).

104 En algún momento entre 1442 y 1446 Martí Sarriera, auditor de las cuentas de la Taula desde por lo menos 1414, parece que decidió jubilarse, y su cargo pasó a manos de Jaume Desquer, alias Puiggenestós. Resulta evidente que al nombrarlo se decidió que Desquer recibiría 450 s.b. en concepto de salario, mientras que Sarriera seguiría recibiendo toda su vida los 1.200 s.b. restantes como agradecimiento por los servicios prestados $(A H C B, 1 \mathrm{~B} . X \mathrm{XI}$, Clavaria, 60, f. 104v, 17-XII-1442; $A H C B, 1 \mathrm{~B} . \mathrm{XI}$, Clavaria, 63, f. 97v, 17-VI-1446).

${ }_{105} A H C B$, 1B.II, Deliberacions, 12, ff. 11v-12v, 25-IV-1458; $A H C B$, 1B.XI, Clavaria, 67, f. 100r, 16-VI1451. En 1451 los 1.650 s.b. seguían estando repartidos entre Desquer y Sarriera. 
ésser condecentment remunerat e assalariat, havent esguart a la qualitat e xtensitat de l'offici". La reclamación, sin embargo, no recibió respuesta alguna hasta casi un año más tarde, cuando se acordó que a cada auditor se le darían 1.400 s.b. anuales ${ }^{106}$. Este fue el sueldo de los oïdors hasta 1468, cuando, a raíz de la suspensión de pagos de la Taula de Canvi, el municipio tomó distintas medidas para limitar sus gastos, entre las cuales la disposición de pagar cada año al entonces auditor único 1.200 s.b. ${ }^{107}$. En 1474, cuando se decidió recuperar la figura del segundo oïdor, el salario no se alteró, de modo que quedó establecido que los 1.200 s.b. se tendrían que dividir entre los dos, recibiendo cada uno 600 s.b. anuales ${ }^{108}$.

\section{La taula del contrast}

Por último, a pesar de no formar parte estrictamente de la Taula de Canvi, también conviene recordar la existencia de la taula del contrast, también llamada taula de la justícia o taula del pes dels florins. Fue el rey Martín el Humano quien el 17 de febrero de 1407 autorizó los consellers de Barcelona a establecerla donde creyeran oportuno, siendo finalmente la ubicación elegida la Llotja de Mar, el mismo espacio donde se encontraba la Taula de Canvi ${ }^{109}$. Tal como apunta Carrère, el primer encargado de la nueva taula fue el mercader Pere Fuster, quien sabemos que poco menos de un mes antes hizo un viaje a Valencia para "contrectar ab lo Senyor Rey sobre lo fet del pes dels florins" "110. Desde entonces, y al contrario de lo que pasó en otras ciudades como Cervera, en Barcelona documentamos la taula del pes dels florins durante todo el siglo XV"11.

En su autorización el rey Martín hablaba siempre del "regidor o regidors" de la flamante taula, sin especificar cuánta gente tenía que trabajar en ella. Aparentemente al principio solo hubo un pesador, pero probablemente bastante pronto se debió considerar que el tipo de trabajo que se hacía en la taula requería la presencia de una persona más como mínimo. Puede que esto motivara que a partir de 1410 apareciera un segundo oficial en la taula, llamado ayudante del pesador ${ }^{112}$. Esta jerarquización del personal de la taula

\footnotetext{
106 AHCB, 1B.II, Deliberacions, 12, ff. 174v-175v, 25-X-1459. El Consell de Cent había escogido la comisión que tenía que gestionar esta súplica el 25 de noviembre de 1458. El aumento de sueldo tenía carácter retroactivo, de modo que hasta el ya despedido Granollacs recibió el 29 de octubre de 1459 los 1.436 s.b. que le correspondían por haber ejercido el cargo de ö̈dor durante un año y nueve días $(A H C B, 1 \mathrm{~B} . \mathrm{XI}$, Clavaria, 72, f. 93r, 29-X-1459).

$107 A H C B, 1$ B.II, Deliberacions, 18, f. 98v, 18-II-1468.

108 AHCB, 1B.II, Deliberacions, 22, f. 53v, 25-IV-1474.

${ }^{109}$ La autorización del rey Martín, también válida para la ciudad de Tortosa, se encuentra transcrita en TRÉTON, El llibre de les monedes de Barcelona i dels florins d'or d'Aragó, pp. 161-63. En este documento el rey Martín ya dice que la nueva taula sería "vulgarment appellada la taula del pes dels florins".

110 CARRère, Barcelona: centre économique à l'époque des difficultés, p. 705; Manual de novells ardits, vol. 1, p. 148.

111 En cambio, en Cervera el pes del contrast fue una institución intermitente durante todo el siglo XV (Verdés PiJuan, Administrar les pecúnies $i$ béns de la Universitat, pp. 674-75).

${ }_{112}$ En el libro de clavaria del segundo semestre de 1409 el ayudante todavía no aparece, pero sí lo encontramos en el del segundo semestre del año siguiente ( $A H C B$, 1B.XI, Clavaria, 34, f. 113r, 29-IX-1410).
} 
del pes dels florins se mantuvo hasta algún momento entre 1451 y 1457 , ya que si bien el primer año todavía se pagaba el salario de un regidor y de un auxiliar, en la clavaria del segundo semestre de 1457 ambos son situados al mismo nivel ${ }^{113}$. No fue hasta agosto de 1464 que se puso en entredicho la colegialidad que desde hacía más de cincuenta años caracterizaba los pesadores. El Trentenari, alegando "los pochs affers que fa la Taula del Cambi de la ciutat per la indisposiçió de la guerra", y la consiguiente falta de trabajo para los oficiales de la taula del contrast, decidió que mantener el salario de los dos trabajadores de dicha taula era superfluo ${ }^{114}$. Por lo tanto, se acordó prescindir de uno de ellos, y no hay constancia que se llegara a reinstaurar durante el siglo XV.

En cualquier caso, tanto el pesador como el ayudante en principio eran cargos vitalicios, que eran elegidos por el Trentenari siempre que había una vacante ${ }^{115}$. Además, en 1414 se documenta el pago del salario de un personaje que posteriormente desaparece: un platero encargado de los pesos y balanzas que existía tanto en la Taula de Canvi como en la de la justícia ${ }^{116}$.

¿En qué consistía la taula del pes dels florins? Según el documento expedido por Martín el Humano, tenía que ser un espacio donde hubiera el juego completo de los pesos que había ordenado fabricar ese mismo día ${ }^{117}$, marcados por un lado con las armas reales y por el otro con la cruz del marco de Perpiñán, y que debían servir para dirimir en las diferencias surgidas en los pagos o depósitos hechos con florines y medios florines. El pesador o pesadores, a los cuales dotaba de "plena auctoritat e poder de deffinir e decidir per benefici del dit pes totes qüestions, controvèrsies e debats", tendrían como peso patrón el vulgarmente conocido como mitgé, de 68 florines por marco de Perpiñán, considerado "ver, bo, just e degut". Las directrices marcadas por el monarca se siguieron al pie de la letra, como se ve en la documentación posterior al mencionar cuál era el principal cometido de la taula dels florins: "pesar, ten bé en gros com en menut, tots florins e mig florins de què sobre lo pes de aquels sia debat entre quallsevoll persones, e ancare tots altres qui $\cdot \mathrm{n}$ sient portats per pesar" ${ }^{118}$.

El sueldo percibido por los pesadores de la taula del contrast cambió a lo largo de todo el siglo XV. Así, mientras que durante su primer año de existencia el regidor ganó 1.980 s.b., el año siguiente el salario se le había rebajado drásticamente hasta los 880 s.b. ${ }^{119}$.

\footnotetext{
${ }_{113} A H C B$, 1B.XI, Clavaria, 67, f. 81r, 13-II-1451, y f. 90r, 19-IV-1451; $A H C B$, 1B.XI, Clavaria, 70, f. 95r, 2-XII-1457.

${ }_{114} A H C B$, 1B.II, Deliberacions, 16, f. 136r, 2-VIII-1464. Se acordó que sería Pere Carnisser, sastre, quien mantendría el cargo, mientras que Antoni Sala, mercero, lo perdería. Sin embargo, Carnisser murió poco más de un año después, y Sala ocupó su lugar temporalmente, hasta que Antoni Modoi fue elegido sucesor de Carnisser ( $A H C B$, 1B.XI, Clavaria, 79, f. 84r, 6-III-1466; $A H C B$, 1B.II, Deliberacions, 17, ff. 75r-75v, 25-II-1466).

115 El Trentenari fue el encargado de designar al citado Antoni Modoi como sucesor del difunto Pere Carnisser ( $A H C B$, 1B.II, Deliberacions, 17, ff. 75r-75v, 25-II-1466).

116 AHCB, 1B.XI, Clavaria, 37, f. 136r, 16-VII-1414.

117 TRÉton, El llibre de les monedes de Barcelona i dels florins d'or d'Aragó, pp. 160-61.

118 AHCB, 1B.XI, Clavaria, 67, f. 81r, 13-II-1451.

$119 A H C B, 1 B . X I$, Clavaria, 32, f. 130v, 22-III-1408; $A H C B$, 1B.XI, Clavaria, 33, f. 112r, 31-VIII-1409.
} 
Esta remuneración debería considerarse mucho más adecuada, ya que se mantuvo hasta por lo menos $1451^{120}$. Fue en algún momento entre este año y 1457, probablemente el mismo en que se decidió prescindir del ayudante y nombrar un segundo pesador, cuando se estableció que uno de ellos cobraría 600 s.b. anuales y el otro 500 ${ }^{121}$. Dos años después, los salarios de ambos se habían igualado en 600 s.b. ${ }^{122}$. Pero esta situación no se mantuvo durante demasiado tiempo. En 1466, cuando hacía dos años que se había suprimido uno de los pesadores, el Consell se fijó de nuevo en el ahora único encargado de las monedas, debatiendo si tenía que despedirlo también a él o no ${ }^{123}$. Con todo, finalmente la asamblea acordó conservar el pesador de la taula del contrast, aunque rebajando su salario a 400 s.b. anuales ${ }^{124}$. En noviembre de 1472, acabada ya la guerra civil, el Consell se replanteó la situación argumentando que dicho oficial era una persona pobre, cargada de numerosos niños y que trabajaba mucho en pro de la ciudad ${ }^{125}$. A pesar de la compasión que parecía despertar entre los jurados, su salario no cambió: en 1489 todavía percibía 400 s.b., cantidad que no fue alterada en el plan de reformas llevado a cabo ese año en el municipio ${ }^{126}$. Por lo que respecta al ayudante del pesador, el año 1410 cobraba 330 s.b. por año, pero entre 1419 y 1433 se le aumentó el sueldo a 500 s.b., cantidad que seguía percibiendo en 1451 , antes de su desaparición ${ }^{127}$.

\section{Conclusiones}

Como ya se ha indicado en la introducción, la voluntad de este estudio es aportar un poco de luz a un tema que hasta hoy permanece algo oscuro, como es el de la estructura de la Taula de Canvi de Barcelona (véase la Ilustración 1). Una vez fijada esta, llega el momento de intentar contrastarla con la de otras instituciones similares del siglo XV. Si nos fijamos en el ámbito de la Corona de Aragón, cabe mencionar que el modelo del banco municipal barcelonés fue aplicado en Valencia el año 1407, aunque como es sabido con escaso éxito ${ }^{128}$. A pesar de la corta vida de la Taula valenciana, es

\footnotetext{
${ }^{120}$ AHCB, 1B.XI, Clavaria, 67, f. 90r, 19-IV-1451. En la entrada del 10 de abril de 1426 del dietario del Consell se dice que se había decidido rebajar el salario del pesador de 880 a 600 s.b., pero, por lo que se observa en los libros de clavaria, no parece que ello se llevara a cabo. Es posible que se tratara de una medida temporal, ya que ese mismo día los consellers suspendieron de su oficio el ayudante de pesador, decisión que fue revocada un año después (Manual de novells ardits, vol. 1, p. 245, 250).

121 AHCB, 1B.XI, Clavaria, 70, f. 95r, 2-XII-1457.

${ }^{122} A H C B$, 1B.XI, Clavaria, 72, f. 76v, 28-VII-1459, y f. 87r, 3-IX-1459.

${ }^{123} A H C B$, 1B.II, Deliberacions, 17, f. 145r, 14-XI-1466, y ff. 146v-147r, 15-XI-1466.

${ }^{124} A H C B$, 1B.II, Deliberacions, 17, f. 151r, 26-XI-1466.

${ }^{125} A H C B, 1 B . I I$, Deliberacions, 21, ff. 119v-120v, 27-XI-1472. En la reunión se mencionó que el salario de 400 s.b. que recibía el pesador en ese momento era consecuencia directa del redreç de la Taula de Canvi de 1468, pero, como se ha visto, en realidad se le había rebajado el sueldo dos años antes.

126 Vicens Vives, Ferran II i la ciutat de Barcelona, p. 69.

$127 A H C B$, 1B.XI, Clavaria, 34, f. 113r, 29-IX-1410; $A H C B$, 1B.XI, Clavaria, 38, f. 72v, 24-IX-1419; $A H C B$, 1B.XI, Clavaria, 48, f. 78v, 9-X-1433; $A H C B$, 1B.XI, Clavaria, 67, f. 90r, 19-IV-1451.

128 Sobre la difusión del modelo de la Taula de Canvi, véase Feliu i MonTfort, Els primers llibres de la Taula de Canvi, pp. 60-62.
} 
importante destacar que sus primeras ordenanzas, redactadas en 1408, se inspiraron claramente en el funcionamiento de la Taula de Barcelona: el banco tenía que instalarse en la Llotja y lo regirían dos taulegers - un ciudadano y un mercader-, que ejercerían dos años cobrando $2.000 \mathrm{~s}$. anuales, previo aval de 6.000 florines $^{129}$. Los acompañarían dos escribanos, con un salario de $1.200 \mathrm{~s}$. cada uno. Pasado un año, quizás después de haber comprobado que la normativa de inspiración barcelonesa no se adaptaba bien a la realidad valenciana, aparecieron unas nuevas ordenanzas, en las cuales se establecía que el regidor sería solo uno, el clavario común de la ciudad, y que se mantendría durante un año, conservando, eso sí, el sueldo de $2.000 \mathrm{~s}$. Junto a él trabajaría únicamente un escribano, que recibiría $1.500 \mathrm{~s}$. anuales. Si nos alejamos de los territorios aragoneses y nos trasladamos a Génova, nos encontramos que entre 1408 y 1445 el Banco di San Giorgio estaba dirigido por dos o cuatro gobernadores ${ }^{130}$. Además, contaba con la presencia de un notario, encargado de las escrituras y ayudado por un iuvenis; un cajero para el manejo del dinero, y un faquín para el transporte de la caja. De nuevo, pues, se trata de una estructura muy parecida a la de la Taula de Canvi, y que a la vez probablemente se inspiraba en aquella de los bancos privados.

A través de este somero repaso al organismo de la Taula durante sus primeros cien años de vida, hemos podido ver no solo cuáles eran los cargos habituales y las funciones que tenían asociadas, sino también qué disfunciones eran las más frecuentes. A lo largo de todo el siglo la falta de personal, las peticiones de aumento de salario o los fraudes amenazaron de forma más o menos recurrente el funcionamiento cotidiano de la Taula. En la mayoría de ocasiones el Consell barcelonés fue sensible a los problemas que iban surgiendo. No en vano, se trataba del banco municipal, y si había una institución interesada en su éxito esta era el gobierno de la ciudad. Probablemente fue esto lo que llevó al Consell a aceptar muchas de las peticiones de revisión de sueldos o lo que motivó la modificación de la normativa de la Taula para poder controlar mejor tanto su funcionamiento como la actuación de sus oficiales.

Sin embargo, queda todavía mucho trabajo por hacer. Si bien la investigación aquí presentada pone la primera piedra del conocimiento de la estructura de la Taula de Canvi, el estudio de su composición en el siglo XVI y hasta la transición hacia el Banco de Barcelona en 1609 resulta esencial para comprender adecuadamente el funcionamiento de la institución. Del mismo modo, resultaría interesante poder contar con la nómina de cargos durante el siglo XV, por ejemplo, para así ver qué hombres eran los que dedicaban parte de su tiempo a la Taula o qué significaba para ellos trabajar allí. El escándalo protagonizado por Bernat de Granollacs en 1459, por ejemplo, parece indicar que por lo menos algunos cargos debían ser considerados de cierto prestigio, de modo que es posible imaginar que los empleos de la Taula de Canvi eran codiciados por parte de la sociedad barcelonesa del Cuatrocientos. Así pues, esperamos que en el futuro los interrogantes que sigue planteando la Taula de

\footnotetext{
129 Mayordomo García-Chicote, La Taula de Canvis, pp. 65-67

130 Felloni, "I primi banchi pubblici della Casa di San Giorgio", p. 229.
} 
Canvi vayan respondiéndose, para así conseguir valorar en su justa medida una de las instituciones que más marcó el último siglo medieval de la Ciudad Condal y que constituye una referencia para la historia bancaria europea.

\section{Bibliografía citada}

BAjet Royo, Montserrat, El jurament $i$ el seu significat jurídic al Principat segons el dret general de Catalunya (segles XIII-XVIII). Edició de la «Forma i pràctica de celebrar els juraments $i$ les eleccions a la ciutat de Barcelona en el segle XV», Universitat Pompeu Fabra, Barcelona, 2009.

Batlle i Gallart, Carme, "Els Granollacs, metges de Barcelona (segle XV). De la cort del rei a la beneficiència parroquial", La pobreza y la asistencia a los pobres en la Cataluña medieval, Manuel Riu (dir.), Consejo Superior de Investigaciones Científicas, Barcelona, 1981-1982, vol. 2, pp. 383-414.

Batlle i Gallart, Carme, La crisis social y económica de Barcelona a mediados del siglo XV, Consejo Superior de Investigaciones Científicas, Barcelona, 1973, vol. 1.

Bruniquer i Riera, Esteve Gilabert, Rúbriques de Bruniquer. Cerimonial dels Magnifichs Consellers y Regiment de la Ciutat de Barcelona, ed. Francesc Carreras i Candi y Bartomeu Gunyalons i Bou, Imprempta d'Enrich y Companyía, Barcelona, 1916, vol. 5. CARrÈre, Claude, Barcelona: centre économique à l'époque des difficultés, 1380-1462, Mouton \& Co, París, La Haia, 1967.

Cifuentes i Comamala, Lluís, La ciència en català a l'Edat Mitjana i el Renaixement, Universitat de Barcelona, Universitat de les Illes Balears, Barcelona, Palma de Mallorca, 2006, 2a ed.

Feliu i Montfort, Gaspar, Els primers llibres de la Taula de Canvi de Barcelona, Fundació Noguera, Barcelona, 2016.

Felloni, Giuseppe, "I primi banchi pubblici della Casa di San Giorgio (1408-45)", Banchi pubblici, banchi privati e monti di pietà nell'Europa preindustriale. Amministrazione, techniche operative e ruoli economici (Atti del Convegno - Genova,1-6 ottobre 1990), Atti della Società Ligure di Storia Patria, Nuova Serie, XXXI (CV), Génova, 1991, vol. 1, pp. 225-246.

Felloni, Giuseppe, "Il Banco di San Giorgio ed il suo archivio: una memoria a più valenze", Scritti di Storia Economica, Atti della Società Ligure di Storia Patria, Nuova Serie, XXXVIII (CXII), Génova, 1999, vol. 1, pp. 461-468 (texto originalmente publicado en Società di letture e conversazioni scientifiche, 1996).

Felloni, Giuseppe, "L'archivio della Casa di San Giorgio di Genova (1407-1805) ed il suo ordinamento", Atti della Società Ligure di Storia Patria. Nuova Serie, XXIV (XCVIII), (1986), vol. 1, pp. 352-361. 
Manual de novells ardits, vulgarment apellat dietari del Antich Consell Barceloní, ed. Frederic Schwartz i Luna y Francesc Carreras i Candi, Imprempta de Henrich y Companyía, Barcelona, 1892-1893, vol. 1-2.

Mayordomo García-Chicote, Francisco, La Taula de Canvis. Aportación a la historia de la contabilidad valenciana (siglos XIII-XVII), Universitat de València, Valencia, 2002.

OrTi Gost, Pere, "Les finances municipals de la Barcelona dels segles XIV i XV: Del censal a la Taula de Canvi", Barcelona Quaderns d'Història, 13 (2007), pp. 257-282. Roberds, William, Velde, François R., "Early Public Banks", Money in the Western Legal Tradition: Middle Ages to Bretton Woods, David Fox, Wolfgang Ernst (eds.), Oxford University Press, Oxford, 2016, pp. 321-358.

Tréton, Rodrigue, El llibre de les monedes de Barcelona i dels florins d'or d'Aragó. Compilació redactada per Jaume Garcia, arxiver reial de Barcelona, per a ús de la seca de Perpinyà, Fundació Noguera, Barcelona, 2009.

Usher, Abbott Payson, The early history of deposit banking in Mediterranean Europe, Harvard University Press, Cambridge, 1943, vol. 1.

Verdés Pijuan, Pere, Administrar les pecúnies i béns de la Universitat. La política fiscal i les estratègies financeres d'un municipi a la baixa edat mitjana (Cervera, 1387-1516), Universitat de Barcelona, 2004 (tesis doctoral inédita).

Vicens Vives, Jaume, Ferran II i la ciutat de Barcelona: 1479-1516, Tipografia Emporium, Barcelona, 1936. 
